\title{
Pneumonectomy is safe and effective for non-small cell lung cancer following induction therapy
}

\author{
Abby White ${ }^{1}$, Suden Kucukak ${ }^{1}$, Raphael Bueno ${ }^{1}$, Elliot Servais ${ }^{2}$, Daniel N. Lee ${ }^{1}$, Yolonda Colson ${ }^{1}$, \\ Michael Jaklitsch ${ }^{1}$, Ciaran McNamee ${ }^{1}$, Steven Mentzer ${ }^{1}$, Jon Wee ${ }^{1}$, Scott J. Swanson ${ }^{1}$ \\ ${ }^{1}$ Department of Surgery, Division of Thoracic Surgery, Brigham and Women's Hospital, Boston, MA, USA; ${ }^{2}$ Department of Surgery, Division of \\ Cardiovascular and Thoracic Surgery, Lahey Hospital and Medical Center, Burlington, MA, USA \\ Contributions: (I) Conception and design: SJ Swanson, A White; (II) Administrative support: A White, S Kucukak, DN Lee; (III) Provision of study \\ materials or patients: SJ Swanson, R Bueno, Y Colson, M Jacklitsch, C McNamee, S Mentzer, J Wee; (IV) Collection and assembly of data: A White, \\ S Kucukak, DN Lee; (V) Data analysis and interpretation: SJ Swanson, A White; (VI) Manuscript writing: All authors; (VII) Final approval of \\ manuscript: All authors. \\ Correspondence to: Dr. Abby White. 75 Francis Street, Boston, MA 02115, USA. Email: awhite12@bwh.harvard.edu.
}

\begin{abstract}
Background: Uncertainty surrounds the safety and efficacy of pneumonectomy in the setting of induction chemoradiation for non-small cell lung cancer (NSCLC). We sought to evaluate fifteen years of experience with pneumonectomy with and without induction therapy.

Methods: Over a 15-year period [1999-2014], data were extracted from medical records of patients undergoing pneumonectomy for NSCLC. Primary outcomes were 5-year overall survival and mortality at 30,60 and 90 days following operation. Morbidity data was also reviewed. Statistical comparisons were performed using the Chi-Square test. Kaplan-Meier curves were compared using the log rank test. Significance was defined as a $\mathrm{P}$ value less than 0.05 . Patients with a prior cancer history, bilateral lung nodules and oligometastatic disease at presentation were excluded.

Results: After exclusion criteria were applied, 240 patients were analyzed and 137 (57\%) underwent induction therapy prior to pneumonectomy. Five-year overall survival was $38.5 \%$. Mortality at 90 days was $7.94 \%$. There was no statistically significant difference in perioperative mortality with the addition of induction therapy. In fact, in the subset of patients with N2 disease ( $\mathrm{n}=65)$, induction therapy was associated with improved 5 -year overall survival $(10.7 \%$ vs. $32.7 \%, \mathrm{P}=0.014)$. Thirty-five percent of patients with N2 disease exhibited a complete response in the nodal basin following induction therapy; however, this did not confer a statistically significant overall or disease-free survival benefit.

Conclusions: Pneumonectomy can safely be performed in the setting of induction chemoradiation. In patients with N2 disease, induction therapy may confer a survival benefit when the surgery can be done with limited morbidity and mortality.
\end{abstract}

Keywords: Safety; pneumonectomy; induction

Submitted Jun 15, 2017. Accepted for publication Jul 25, 2017.

doi: $10.21037 /$ jtd.2017.10.92

View this article at: http://dx.doi.org/10.21037/jtd.2017.10.92

\section{Introduction}

The first report of pneumonectomy for lung cancer was published in the fournal of American Medical Association $(7 A M A)$ in 1933 and was performed by Dr. Graham (1). His patient, Dr. Gilmore, an obstetrician from Pittsburgh, would go on to outlive the surgeon himself. As our understanding of the biology of lung cancer and the physiologic consequences of pneumonectomy evolved, so did the techniques and treatments for locally advanced lung cancer, which often include a combination of chemotherapy, radiation and surgery. The Intergroup trial (2), a randomized study published in 2009 and 
comparing neoadjuvant chemoradiotherapy plus surgery to chemoradiotherapy alone, issued caution regarding pneumonectomy in the context of multimodality therapy. This was largely due to inexplicable surgical results in this series, which demonstrated morbidity and mortality higher than published averages (26\%). Yet pneumonectomy continues to be advocated in this setting by high volume centers that achieve superior surgical morbidity and mortality (3-6). Our initial experience in 73 patients demonstrated favorable morbidity and mortality (7). A systematic review of pneumonectomy followed by neoadjuvant therapy was published in 2012 (8). The report included 27 studies from 1990-2010, and included 4 randomized controlled studies, including the Intergroup trial. Mortality at 30 days was $7 \%$ and at 90 days was $12 \%$, suggesting traditional reporting of 30-day mortality may not be the ideal marker of perioperative mortality for pneumonectomy patients. A recently published query of a large-volume national database; however, suggests patients with stage IIIA non-small cell lung cancer (NSCLC) receive neoadjuvant chemoradiotherapy without survival benefit over upfront surgery with adjuvant therapy (9). Importantly, patients with final positive margins were excluded, and mortality was only reported at 30-days. The ideal treatment for patients with locally advanced NSCLC, who require pneumonectomy for resection, remains controversial. This study sought to evaluate the safety and efficacy of pneumonectomy following neoadjuvant chemoradiation therapy in our institution over a 15 -year period.

\section{Methods}

Institutional Review Board approval was obtained to perform this retrospective review. Individual patient consent was waived for this retrospective study. The age, gender, histopathology, preoperative staging, 90-day mortality, major complications, and survival were recorded for all patients undergoing pneumonectomy for lung cancer at our institution between 1999 and 2014. Patients with a prior history of cancer, with pathology other than NSCLC, and patients with bilateral lung nodules or oligometastatic disease at presentation were excluded from the study. Our institution was involved in a study evaluating the efficacy of extrapleural pneumonectomy for NSCLC in the setting of pleural disease (IIIB). These patients and others undergoing extrapleural pneumonectomy were excluded. Nodal disease was confirmed by histopathology in $81.5 \%$ of patients prior to induction therapy. In the remaining
$19.5 \%$ of patients, mediastinal nodal stations were positron emission tomography (PET)-avid and presumed positive. Median length of follow-up was 2.2 years. Tumors were classified and re-staged according to the 7 th edition of the International System for Staging of Lung Cancer. The statistical analysis was performed using STATA 14.1 (Stata Statistical Software, StataCorp LP, College Station, TX, USA). The comparative analysis of the differences between the two groups was performed with the Chi-Square test. Survival was calculated using the Kaplan-Meier method and were statistically evaluated by the log-rank test. A P value of less than 0.05 was considered significant.

\section{Results}

Following application of exclusion criteria, 240 patients who underwent pneumonectomy for lung cancer at our institution were analyzed. The most common histology was squamous cell carcinoma $(53.3 \%)$, followed by adenocarcinoma, and poorly differentiated NSCLC (Table 1).

Of those, 137 (57\%) underwent induction therapy prior to surgery, $79 \%$ received chemoradiation and $21 \%$ received chemotherapy alone. There were 65 patients with pathologic N2 disease, and A total of 46 patients underwent induction therapy specifically for this purpose. Twentyseven patients underwent extended pneumonectomy, which included chest wall resection, partial vertebrectomy, superior vena cava resection and reconstruction, or diaphragmatic resection and reconstruction, in addition to pneumonectomy. Twenty percent of these patients were alive at 5 years.

The overall 5 -year survival for all 240 patients was $38.5 \%$, and was not significantly different for patients with or without induction therapy $(\mathrm{P}=0.4490)$ (Figure 1 and Table 2). Not surprisingly, the presence of nodal disease conferred a worse prognosis (Figure 2). However, 46 patients underwent induction therapy for $\mathrm{N} 2$ disease and this subset of patients exhibited a three-fold increase in 5 -year overall survival compared to those patients with $\mathrm{N} 2$ disease who did not receive induction therapy $(32.7 \%$ vs. $10.7 \%, \mathrm{P}=0.0141$ ) (Table 2). Disease-free survival at 5 years was also statistically better for patients with $\mathrm{N} 2$ disease who underwent induction therapy prior to pneumonectomy (22.9\% vs. $11.5 \%, \mathrm{P}=0.033)$. Mortality at $30-, 60-$, and 90 -days was $2.08 \%, 5.0 \%$, and $7.94 \%$, respectively. The most common complication was atrial arrhythmia, affecting $27.5 \%$ of patients. Bronchopleural fistula (1.7\%), empyema, adult respiratory distress syndrome (ARDS) (2.9\%), vocal 
Table 1 Characteristics of patients undergoing pneumonectomy for NSCLC, no induction vs. induction, 1999-2014 (N=240)

\begin{tabular}{|c|c|c|c|c|}
\hline Characteristics & Total patients $(\mathrm{N}=240)$ & Patients with no induction ( $\mathrm{N}=103$ ) & Patients with induction $(\mathrm{N}=137)$ & $P$ value \\
\hline \multicolumn{5}{|l|}{ Age } \\
\hline Mean & 62.78 & 65.91 & 60.42 & 0.508 \\
\hline Min & 37.24 & 43.8 & 37.24 & \\
\hline Female & $91(37.9 \%)$ & $37(35.9 \%)$ & $54(39.4 \%)$ & 0.581 \\
\hline Male & $149(62.1 \%)$ & $66(64.1 \%)$ & $83(60.6 \%)$ & \\
\hline \multicolumn{5}{|l|}{ Smoking status } \\
\hline Never & 12 & 5 & 7 & 0.928 \\
\hline No info & 23 & 10 & 13 & 0.954 \\
\hline \multicolumn{5}{|l|}{ Lung laterality } \\
\hline Left & 148 & 64 & 84 & 0.897 \\
\hline Right & 92 & 39 & 53 & \\
\hline \multicolumn{5}{|l|}{ Tumor histology } \\
\hline Squamous cell carcinoma & $128(53.3 \%)$ & $64(62.1 \%)$ & $64(46.7 \%)$ & 0.018 \\
\hline Adenocarcinoma & $87(36.3 \%)$ & $31(30.1 \%)$ & $56(40.9 \%)$ & 0.086 \\
\hline Poorly differentiated & $17(7.1 \%)$ & $4(3.9 \%)$ & $13(9.5 \%)$ & 0.094 \\
\hline Stage III & $101(42.1 \%)$ & $51(49.5 \%)$ & $50(36.5 \%)$ & 0.043 \\
\hline \multicolumn{5}{|l|}{ Stage III by TNM classification } \\
\hline T4NO & $9(8.9 \%)$ & $3(5.9 \%)$ & $6(12.0 \%)$ & 0.281 \\
\hline T3N1 & $41(40.6 \%)$ & $30(58.8 \%)$ & $11(22.0 \%)$ & 0.000 \\
\hline T4N1 & $7(6.9 \%)$ & $4(7.8 \%)$ & $3(6.0 \%)$ & 0.715 \\
\hline T0-2bN2 & $22(21.8 \%)$ & $4(7.8 \%)$ & $18(36.0 \%)$ & 0.001 \\
\hline T3N2 & $15(14.9 \%)$ & $6(11.8 \%)$ & $9(18.0 \%)$ & 0.378 \\
\hline T4N2 & $7(6.9 \%)$ & $4(7.8 \%)$ & $3(6.0 \%)$ & 0.715 \\
\hline \multicolumn{5}{|l|}{ Tumor size $(\mathrm{cm})$} \\
\hline Mean & $4.99 \pm 2.91$ & $5.79 \pm 2.66$ & $4.38 \pm 2.95$ & 0.390 \\
\hline Median & 4.8 & 5.5 & 4.3 & \\
\hline Maximum & 15 & 15 & 15 & \\
\hline
\end{tabular}

NSCLC, non-small cell lung cancer. 


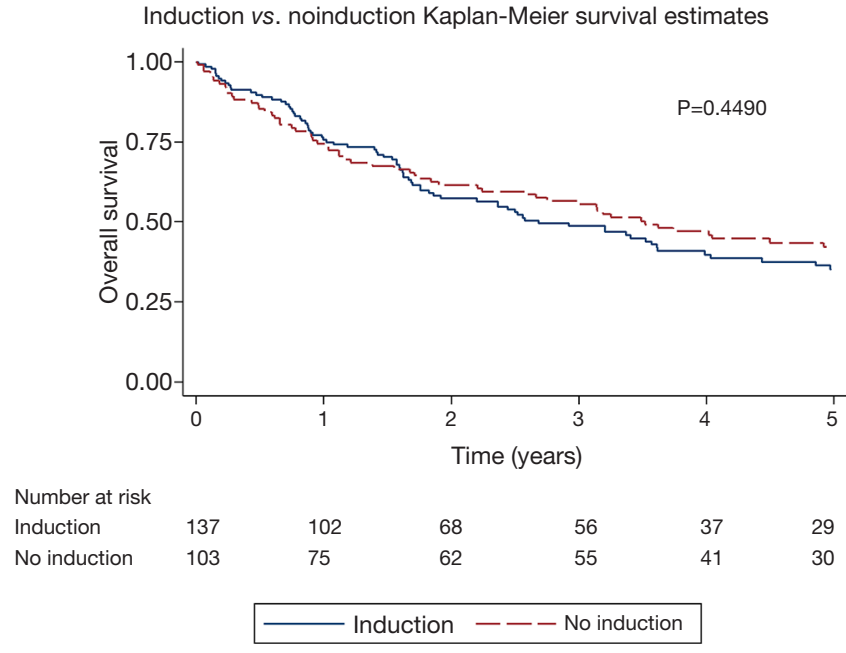

Figure 1 Kaplan-Meier curve for patients undergoing pneumonectomy for NSCLC [1999-2014] with and without induction therapy (central figure). NSCLC, non-small cell lung cancer.

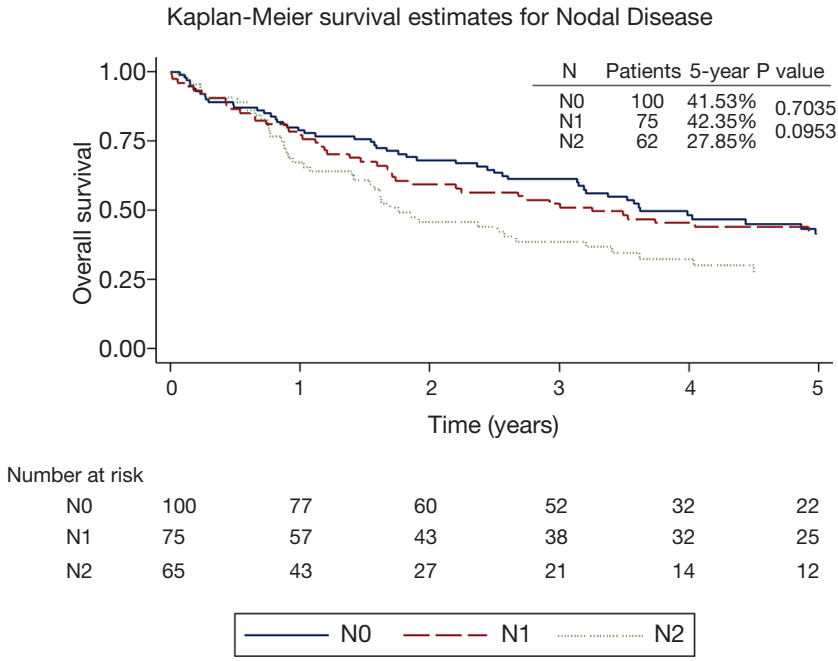

Figure 2 Kaplan-Meier curve for patients undergoing pneumonectomy for NSCLC [1999-2014] stratified by nodal disease.

Table 2 Five-year survival for patients who underwent pneumonectomy for NSCLC, with and without induction therapy (N=240)

\begin{tabular}{|c|c|c|c|c|c|c|c|c|c|c|c|}
\hline \multirow{2}{*}{ Patient characteristics } & \multicolumn{2}{|c|}{ Total patients } & \multicolumn{2}{|c|}{ Survival at 5-years } & \multirow{2}{*}{$P$ value } & \multicolumn{2}{|c|}{ Mortality at 30 -days } & \multicolumn{2}{|c|}{ Mortality at 60 -days } & \multicolumn{2}{|c|}{ Mortality at 90-days } \\
\hline & $\mathrm{N}$ & $\%$ & Alive $\mathrm{N}$ & $\%$ & & Events $\mathrm{N}$ & $\%$ & Events $\mathrm{N}$ & $\%$ & Events $\mathrm{N}$ & $\%$ \\
\hline \multicolumn{12}{|l|}{ Overall survival } \\
\hline $\begin{array}{l}\text { Patients with no } \\
\text { induction therapy }\end{array}$ & 103 & 42.9 & 30 & 42.2 & 0.449 & 3 & 2.9 & 6 & 5.8 & 10 & 9.8 \\
\hline $\begin{array}{l}\text { Patients with induction } \\
\text { therapy }\end{array}$ & 137 & 57.1 & 29 & 35.3 & & 2 & 1.5 & 6 & 4.4 & 9 & 6.6 \\
\hline Total & 240 & 100 & 59 & 38.5 & & 5 & 2.1 & 12 & 5 & 19 & 7.9 \\
\hline \multicolumn{12}{|l|}{ Overall survival-N2 } \\
\hline $\begin{array}{l}\text { Patients with no } \\
\text { induction therapy }\end{array}$ & 14 & 21.5 & 1 & 10.7 & 0.014 & 1 & 7.1 & 2 & 14.3 & 4 & 28.6 \\
\hline $\begin{array}{l}\text { Patients with induction } \\
\text { therapy }\end{array}$ & 51 & 78.5 & 11 & 32.7 & & 0 & 0 & 1 & 2 & 1 & 2 \\
\hline Total & 65 & 100 & 12 & 27.9 & & 1 & 1.5 & 3 & 4.6 & 5 & 7.7 \\
\hline
\end{tabular}

cord paralysis $(5.0 \%)$, pulmonary embolism $(2.5 \%)$, and pneumonia $(4.2 \%)$ were much less common, and similar among both groups of patients (Table 3). Fourteen (5.8\%) patients had final positive margins.

Fifteen $(10.95 \%)$ of the 137 patients who underwent induction therapy demonstrated complete response on their final pathology, with a 5 -year OS of $46.3 \%$ (Table 4). Sixteen of the 46 patients with N2 disease prior to induction therapy
(34.8\%) demonstrated pathologic response in the N2 nodal bed, defined as no residual tumor. There was no difference in survival in patients with nodal response compared to those without nodal response to induction therapy $(35.0 \%$ vs. $29.7 \%$ ) (Table 4), nor was there a difference in survival among patients with single-station versus multi-station $\mathrm{N} 2$ disease $(27.5 \%$ vs. $28.4 \%, \mathrm{P}=0.669)$. The most common histology found on final pathologic review for patients with 
Table 3 Non-arrhythmia complications of pneumonectomy for NSCLC with and without induction therapy

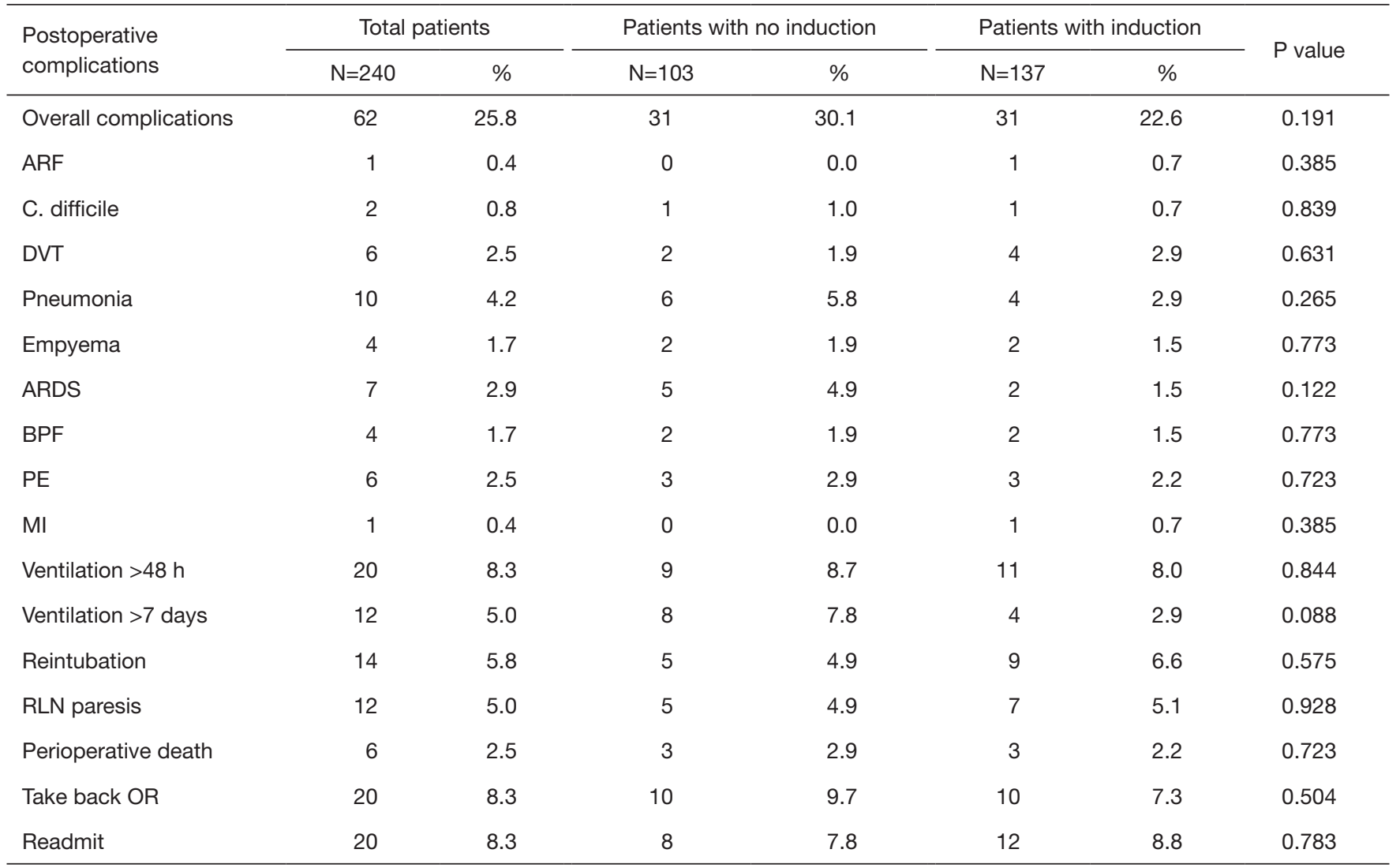

ARDS, adult respiratory distress syndrome; BPF, broncopleural fistula; PE, pulmonary embolism; MI, myocardial infarction; DVT, deep vein thrombosis; ARF, acute renal failure; RLN, recurrent laryngeal nerve; OR, operating room.

Table 4 Survival in patients with and without pathologic response to induction therapy

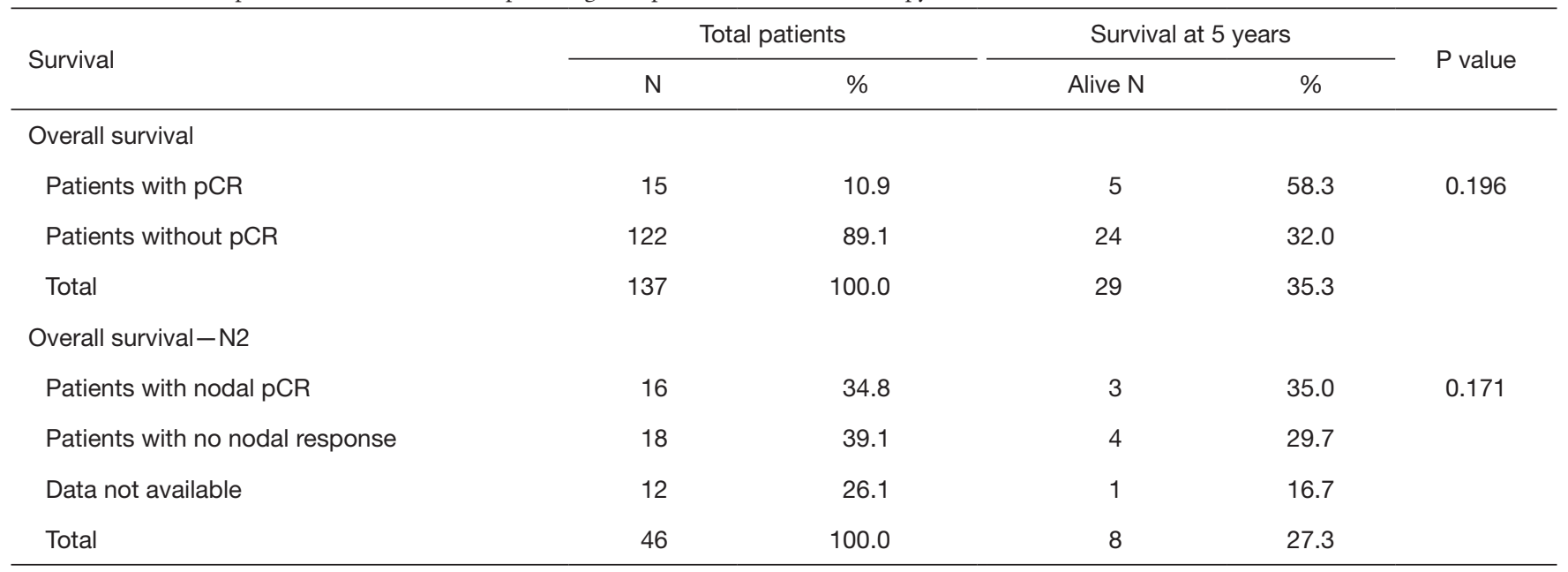


$\mathrm{N} 2$ disease and response to induction chemoradiation, was adenocarcinoma $(\mathrm{n}=10,62.5 \%)$.

\section{Discussion}

Early case series evaluating pneumonectomy following induction chemoradiation reviewed small study populations and reported mortality rates as high as $45 \%$ (10). Subsequent data, from a randomized study evaluating surgery for lung cancer following chemoradiation, continued to question the safety of performing pneumonectomy in that setting (2). The 90 -day mortality rate of $6.6 \%$ reported in this study for patients who underwent induction therapy prior to surgery, is well below the 30-day mortality reported in many studies in the absence of induction therapy, suggesting that pneumonectomy can be safely performed in the setting of induction therapy. Furthermore, the data presented here suggests that induction therapy confers a definite benefit in the subset of patients with N2 disease.

The findings regarding nodal response in patients with $\mathrm{N} 2$ disease are important, but warrant further investigation. Our institution has reported on the prognosis of lymph node disease following chemoradiation previously (11). Traditionally, down-staging after induction therapy has been consistent with the hypothesis that the absence of lymphatic involvement at the time of surgery is a predictive marker for the eradication of systemic disease, and is expected to confer at least some cancer-specific survival benefit. While our data indicates that surgery after induction therapy can be accomplished without compromising morbidity or mortality, our study failed to demonstrate a survival benefit with induction therapy despite achieving a complete response in nodal pathology in over $30 \%$ of patients. What's more, there was no detectable difference in survival whether nodal disease was single- or multi-station. The survival benefit found for patients who underwent induction therapy compared to those that underwent upfront surgery for N2 disease is intriguing and warrants further review in larger controlled studies. Practically speaking, patients in this subgroup are heterogeneous and not all can expect to benefit from such an aggressive treatment strategy.

The need for additional or extended resection (chest wall resection, left atrial resection, diaphragmatic resection, etc.) in and of itself implies a more invasive tumor. That said, $21 \%$ of the patients undergoing extended pneumonectomy were alive at 5 years, and that has significant implications on treatment options, particularly with young and fit patients that wish to be aggressive with treatment strategy.
Our retrospective review has several limitations. While 240 patients are a substantial experience, it may not be an adequate sample size to detect subtle differences in survival among the treatment strategies. Also, out-of-state patients were challenging to track longitudinally, as evidenced by a median follow up of 2.2 years. Patients selected for surgery likely represented patients with favorable physiologic and functional profiles, and we have not included patients who received chemoradiation with the intention of resection, but never went on to surgery, nor patients who were downstaged to a lobectomy, or bilobectomy or sleeve resection following induction therapy. Twelve patients had induction therapy for N2 disease but did not have that station sampled at the time of surgery. Some of the operative reports suggested a particular lymph node basin was surveyed but no lymph nodes were found following induction therapy, but this was not recorded as a nodal response, given the lack of pathologic tissue confirmation. An additional consideration are patients who underwent pneumonectomy prior to any systemic therapy due to concerns related to hemoptysis or post-obstructive pneumonia, which may have negatively affected survival data and perioperative morbidity and mortality data in the upfront surgery group.

\section{Conclusions}

Pneumonectomy can be safely performed following induction chemoradiation for NSCLC, achieving morbidity and mortality rates comparable to national standards without chemoradiation. There was a survival benefit to induction therapy prior to pneumonectomy for patients with N2 disease, though cohort size was small. Though $34.8 \%$ of patients exhibited a complete pathologic nodal response on final pathology in response to induction therapy, this did not confer a measurable survival benefit at 5 years.

Pneumonectomy continues to be a valid treatment strategy for patients with NSCLC and our study suggests it continues to play a role in multimodality therapy.

\section{Acknowledgements}

None.

\section{Footnote}

Conflicts of Interest: The authors have no conflicts of interest to declare. 
Ethical Statement: The study was approved by institutional ethics board of Partners Healthcare (No. 2006P002482). Individual patient consent was waived for this retrospective study.

\section{References}

1. Graham EA, Singer JJ. Successful removal of an entire lung for carcinoma of the bronchus. JAMA 1933;101:1371-74.

2. Albain KS, Swann RS, Rusch VW, et al. Radiotherapy plus chemotherapy with or without surgical resection for stage III non-small-cell lung cancer: a phase III randomised controlled trial. Lancet 2009;374:379-86.

3. Kim AW, Faber LP, Warren WH, et al. Pneumonectomy after chemoradiation therapy for non-small cell lung cancer: does "side" really matter? Ann Thorac Surg 2009;88:937-43; discussion 944.

4. Weder W, Collaud S, Eberhardt WE, et al. Pneumonectomy is a valuable treatment option after neoadjuvant therapy for stage III non-small-cell lung cancer. J Thorac Cardiovasc Surg 2010;139:1424-30.

5. Krasna MJ, Gamliel Z, Burrows WM, et al. Pneumonectomy for lung cancer after preoperative concurrent chemotherapy and high-dose radiation. Ann Thorac Surg 2010;89:200-6; discussion 206.

Cite this article as: White A, Kucukak S, Bueno R, Servais E, Lee DN, Colson Y, Jaklitsch M, McNamee C, Mentzer S, Wee J, Swanson SJ. Pneumonectomy is safe and effective for nonsmall cell lung cancer following induction therapy. J Thorac Dis 2017;9(11):4447-4453. doi: 10.21037/jtd.2017.10.92
6. Cerfolio RJ, Bryant AS, Jones VL, et al. Pulmonary resection after concurrent chemotherapy and high dose (60Gy) radiation for non-small cell lung cancer is safe and may provide increased survival. Eur J Cardiothorac Surg 2009;35:718-23; discussion 723.

7. Kim AW, Boffa DJ, Wang Z, et al. An analysis, systematic review, and meta-analysis of the perioperative mortality after neoadjuvant therapy and pneumonectomy for non-small cell lung cancer. J Thorac Cardiovasc Surg 2012;143:55-63.

8. Allen AM, Mentzer SJ, Yeap BY, et al. Pneumonectomy after chemoradiation: the Dana-Farber Cancer Institute/ Brigham and Women's Hospital experience. Cancer 2008;112:1106-13.

9. Broderick SR, Patel AP, Crabtree TD, et al. Pneumonectomy for Clinical Stage IIIA Non-Small Cell Lung Cancer: The Effect of Neoadjuvant Therapy. Ann Thorac Surg 2016;101:451-7; discussion 457-8.

10. Cyjon A, Nili M, Fink G, et al. Advanced non-small cell lung cancer: induction chemotherapy and chemoradiation before operation. Ann Thorac Surg 2002;74:342-7.

11. Bueno R, Richards WG, Swanson SJ, et al. Nodal stage after induction therapy for stage IIIA lung cancer determines patient survival. Ann Thorac Surg 2000;70:1826-31. 